\title{
Die polnischen Absagebriefe während der Kriege mit dem Deutschen Orden
}

\section{The Polish Letters of Feud Declaration during the Wars with the Teutonic Order}

\author{
Adam Szweda / aszweda@umk.pl \\ Instytut Historii i Archiwistyki UMK w Toruniu, PL
}

\begin{abstract}
A medieval war demanded an officially written declaration. Polish war declarations from the time of war with the Teutonic Order are an integral part of war and political culture of that time. In construction the declarations were written analogically to ones in neighbouring countries. They were written in Latin, sometimes in German. In 1454 a gauche Polish language made its presence. In the last war of the Order (1519-1521), the documents were uniformly in Polish and the royal chancellery attempted with some success to establish a uniform model for the drafting of war declarations.
\end{abstract}

\section{Keywords}

Medieval War; Feud; Feud Letter; Poland; Teutonic Order

Der vorliegende Aufsatz entstand im Rahmen des von der Narodowe Centrum Nauki (Polska) / National Science Center (Poland) geförderten Forschungsprojektes Nr. 2018/29/B/HS3/00793 "Royal Vassals. In Search of a Model of Relations between Polish Kings and Dependent Lords (from the second half of the 14th Century until the early 16th Century)." 
Die Art und Weise, wie es im Mittelalter zu verschiedenen Waffenkonflikten kam, wurde auch von den sich evolutionär entwickelnden Rechtsregelungen bestimmt, die unkontrollierten Gewaltakten vorbeugen sollten. Einer Fehde, bei der feindliche Maßnahmen ergriffen wurden (unabhängig davon, ob es sich dabei um entzweite Ritter, Adlige oder Herrscher handelte), ging deswegen eine frühere Absage voraus (diffidatio), die seit dem 13. Jahrhundert eine schriftliche Form des Absagebriefes annahm. ${ }^{1}$ In der polnischen Sprache wird die Absage mithilfe von „odpowiedź“, wiedergegeben (offizielle Ankündigung einer Rache, Revanche), das Verb dagegen mithilfe von „odpowiedzieć“. ${ }^{2}$ Aus diesem Grund spricht man hier vom polnischen „list odpowiedni“, obwohl die moderne Literatur nicht selten auch die Form „list wypowiedni“ bevorzugt. Die beiden Begriffe sind dabei auf Deutsch als «Absagebrief» zu übersetzen. Otto Bruner charakterisierte kurz die Binnenstruktur ähnlicher Urkunden: „Die Absagebriefe sind meist kurz, sie stellen nur fest, dass dem Absager vom Befehdeten Unrecht geschehen sei, ohne die Rechtslage näher darzustellen. Dann enthalten sie die Erklärung, dass der Absagende seines Gegners und dessen Helfer Feind sein und mit diesem Brief seine Ehre bewahren wolle. Diese Formel wird sagen, dass der Fehdeführende durch seine Gewalttaten nicht ehr- und rechtlos wird." ${ }^{3}$ Der besagte Forscher bemerkte ebenfalls, dass an der Fehde nicht nur die Hauptparteien beteiligt waren, sondern auch ihre „Verbündeten, Anhänger, Helfer und Bediensteten“. Darauf sind im europäischen Westen zahlreiche Absagebriefe zurückzuführen, die von den Söldneranführern, häufig Hofleuten eines Gewalthabers, ausgestellt wurden. ${ }^{4}$ Wenn sie ihre Schreiben an einen in der Sozialhierarchie höhergestellten Empfänger richteten, bedienten sie sich aller Höflichkeitsformeln, obwohl sie damit doch ihre feindlichen Absichten ankündigen wollten. ${ }^{5}$

Die Absagebriefe gehören zum Genre litterae patentes, d.h. sie wurden nicht versiegelt - das Siegel befand sich auf dem Papier unter dem Text. ${ }^{6}$

1 Zur Fachliteratur über die Fehde und die Absage siehe zuletzt: Fehdehandeln und Fehdegruppen im spätmittelalterlichen und frühneuzeitlichen Europa. Hg. von M. Prange - Ch. Reinle. Göttingen 2014; Janiš, Dalibor - Janišová, Jana: Fehde und Krieg im böhmischen und mährischen Landrecht des Spätmittelalters. In: Kommunikation im Krieg (im Druck); Szweda, Adam: Was geschieht, bevor der Krieg beginnt? Das Beispiel der Beziehungen zwischen Polen-Litauen und dem Deutschen Orden bis 1454. In: Kommunikation im Krieg (im Druck) - hier auch die weitere Literatur; siehe auch die unten angeführten Bearbeitungen.

2 Stownik staropolski V. Hg. von S. Urbańczyk u. a. Wrocław 1965-1969, S. 488 und Beispiel: „(Micos) illud, quod faciebat, hoc faciebat ibidem Bohemie za odpowedzą [!], prout bonus homo“ (1429), S. 487, und Beispiel: „Diffidavit sibi alias odpowyedzal“ (1424).

3 Brunner, Otto: Land und Herrschaft. Grundfragen der territorialen Verfassungsgeschichte Österreichs im Mittelalter. Brünn 1943, S. 84. Derartige Formulierungen aus den Absagebriefen wurden von K. Łopatecki falsch verstanden (Łopatecki, Karol: „Disciplina militaris“w wojskach Rzeczypospolitej do potowy XVII wieku. Białystok 2012, S. 47), ihm zufolge hätten sie den Söldnerrottmeister - abgesehen vom Eid - zusätzlich an den Herrscher gebunden und sollten Verrat und Aufruhr, also den Plagen der zeitgenössischen Söldnerheere, vorbeugen.

4 Brunner, O.: Land und Herrschaft, S. 84-86.

5 Reinle, Christine: Scheltworte, Schandbilder, Absagen: Kommunikation vor, während und über Fehden. In: Kommunikationsnetze des Ritteradels im Reich um 1500. Hg. von J. Schneider. Stuttgart 2012, S. 139.

6 Rösener, Werner: Fehdebrief und Fehdewesen. Formen der Kommunikation beim Adel im späteren Mittelalter. In: Kommunikationspraxis und Korrespondenzwesen im Mittelalter und in der Renaissance. Hg. von H. - D. Heimann in Verbindung mit I. Hlaváček. Paderborn 1998, S. 96. 
Unter vielen ähnlichen Quellen aus dem Spätmittelalter und den Anfängen der Neuzeit stellen die an die Hochmeister des Deutschen Ordens gerichteten polnischen Absagebriefe die Mehrheit. Sie sind dank einer guten Arbeitsorganisation des Ordensarchivs, in dem sie sorgfältig aufbewahrt wurden, erhalten geblieben. Andere Bestände sind nur ergänzend dazu zu betrachten. Briefe, die an andere Empfänger als an die Ordensritter, gesendet wurden, fanden sich verstreut über viele Orte vor, weil sie im Unterschied zu den eigentlichen Urkunden für gewöhnlich nicht aufbewahrt wurden. ${ }^{7}$ Aus diesem Grund sind die Absagebriefe, die die Beziehungen zwischen Polen und dem Deutschen Orden schildern, eine wertvolle Quelle zur Erforschung der bisher relativ wenig untersuchten polnischen Diplomatie. Es ist also sinnvoll, eine eingehende Analyse vor allem in Bezug auf ihre formalen Merkmale wie Sprache bzw. Inhaltsstruktur durchzuführen.

In den Quellen stößt man auf eine Reihe von Beispielen, die die gegenseitigen feindlichen Akte zwischen den Untertanen beider Parteien, d.i. des Königs und des Hochmeisters, vom Ausgang des 14. Jahrhunderts bis zu den 1440er Jahren bestätigen. Mit der Zeit wurden sie aber immer seltener. In den einschlägigen Klagen betonte man, dass die Absage vorher nicht angekündigt wurde, bzw. man wies darauf hin, dass sich die Angreifer nicht weigerten, sie auszustellen. ${ }^{8}$ Wir verfügen über keine ähnlichen erhaltenen Briefe und können von daher ihre formalen Merkmale nicht detailliert schildern.

Der erste Anlass, aus dem die mit dem polnischen König verbündeten Personen ihre Absagebriefe anfertigen konnten, bot sich nach Ablauf des Waffenstillstands im Krieg zwischen Polen und dem Deutschen Orden, der seit Juni 1409 geführt worden war. Den ursprünglichen Beschlüssen zufolge kam es dazu am 24. Juni 1410, doch wurde der Waffenstillstand infolge weiterer diplomatischer Bemühungen bis zum 4. Juli verlängert. ${ }^{9} \mathrm{Zu}$ Julianfang (die Quelle führt keine Datenformel an) stellte der Lehnsmann der polnischen Krone und Herzog von Masowien Siemowit IV. seinen Brief aus, und zwar auf Latein. Der Ausstellende bestätigte seine Freundschaftsbeziehung zum Hochmeister und dem Orden (Semovitus [...] magistro Prussie et ordini amiciciam nostram) und benachrichtigte bzw. warnte die Empfänger, dass er angesichts der neuen Umstände (secundum cursum, qui nunc vadit) König Ladislaus Jagiełło und Großfürst Vitold zur Seite stehen und ihre "Gerechtigkeit“ bestätigen werde (damus vobis scire per hanc paginam, quia precustodimus vobis, te magister et ordinem [...] quia volumus circa [...] Wladislaum regem Polonie ac [...] Allexandrum alias Witowdum supremum [!] ducem Litphanie stare et iusticiam ipsorum

7 Aus diesem Grund stößt man seltener auf Briefe aus anderen Kriegsgebieten, wie etwa auf die auf Böhmisch 1491 verfassten Briefe der Rottmeister, die im Dienste Jan Olbrachts standen, als er um die ungarische Krone kämpfte - Łopatecki, K.: „Disciplina militaris“, S. 43.

8 Szweda, Adam: Feud in medieval Poland: an introduction into the concept. In: Fehdehandeln und Fehdegruppen, S. 95-96. Die Friedensverträge zwischen Polen und dem Deutschen Orden von 1422 und 1435 führten ein praktisches Verbot der privaten Fehde in nachbarschaftlichen Beziehungen und somit auch der „Absage“ ein. Man untersagte, denjenigen Personen Zuflucht zu bieten, die eine solche Tat im Nachbarland begangen hatten - Die Staatsverträge des Deutschen Ordens in Preussen im 15. Jahrhundert. Bd. I. Ed. E. Weise. Marburg 1970², S. 181, Nr. 154.

9 Kwiatkowski, Krzysztof: Wyprawa letnia 1410 roku. In: Jóźwiak, Sławomir - Kwiatkowski, Krzysztof - Szweda, Adam - Szybkowski, Sobiesław: Wojna Polski i Litwy z Zakonem Krzyżackim w latach 1409-1411. Malbork 2010, S. 301. 
subportare $).{ }^{10}$ In dieser knappen Urkunde fehlten klare Formulierungen, und die darin erklärte Freundschaftsbeziehung des Herzogs gegenüber dem Orden war mehr als nur eine formelhafte Aussage. Obwohl der Herzog von Masowien ein loyaler Lehnsmann des Königs war, lieh er für einen Teil seiner Güter mehrmals Geld von den Ordensvorstehern und beteiligte sich 1409 an jenen Handlungen, deren Ziel es war, einem Ausbruch des Konflikts zwischen Polen und dem Deutschen Orden vorzubeugen. ${ }^{11}$

Der erste Konflikt, bei dem sich die polnische (und litauische) Partei als streitlustig erwies, war der sog. Hungerkrieg von 1414. Sein Ausbruch ging direkt auf die Politik des polnischen Königs Ladislaus Jagiełło und des litauischen Großfürsten Alexander Vitold zurück, die schon seit Frühherbst 1411 bestrebt waren, die Beschlüsse des Ersten Thorner Friedens zu revidieren und über den abgeschwächten Orden die Oberhand zu gewinnen. ${ }^{12}$ Der Krieg brach infolge des Absagebriefes von König Ladislaus Jagiełło aus, der am 29. Juni 1414 in Lenczyca / Łęczyca verfasst worden war. Im Unterschied zu anderen derartigen Quellen wurde er auf Pergament niedergeschrieben. Der Ausstellende, der sich allgemein auf die einzelnen Fälle der vom Deutschen Orden missachteten Beschlüsse des Thorner Friedens berief, stellte fest, dass er seinen bewaffneten Angriff ohne Absage hätte beginnen können. Der König erklärte aber hingegen, dass er dies nicht tue, um allen Rechtsforderungen Genüge zu tun. Diesen Äußerungen folgte die eigentliche Absageformel: omnibus favoribus, amiciciis et benivolenciis, quibus vos, ordinem, coadiutores et subditos vestros predictos fuimus prosequti, renuncciamus et finem imponimus per presentes. Die Urkunde wird von der Anrede an Gott und der Bitte um Beistand der Gottesmutter, aller Heiligen sowie der (bereits nach der Datierung und Korroboration hinzugefügten) königlichen Patrone und Bischöfe Stanislaus und Adalbert abgeschlossen. ${ }^{13}$

Das Heer, das zum Feldzug im Jahr 1414 angeworben wurde, war zahlenmäßig den polnisch-litauischen Streitkräften vom Sommerkrieg 1410 überlegen. Außer dem Landsturm beteiligten sich zahlreiche Söldnerrotten sowie eine Vielzahl von schlesischen Herzögen am Krieg. Dies bestätigt die Anziehungskraft von König Ladislaus Jagiełło, der aus der Schlacht bei Tannenberg siegreich hervorging. Viele Personen, darunter der König selbst, wovon der Verlauf der Anfangsphase des Krieges zeugt, hofften erneut auf einen Sieg. ${ }^{14}$ Das bewirkte, dass sich relativ viele Absagebriefe aus der Zeit vor den Militärkämpfen erhalten haben, die von den im Dienst Ladislaus Jagiełłos stehenden böh-

10 Codex epistolaris Vitoldi, magni ducis Lithuaniae 1376-1430 (= CEV). Ed. A. Prochaska. Kraków 1882, S. 211, Nr. 449. Die in polnischen Diensten stehenden schlesischen und böhmischen Söldner stellten ebenfalls ihre Absagebriefe aus - CEV, S. 211-212, Nr. 450, 451.

11 Supruniuk, Anna: Mazowsze Siemowitów (1341-1442). Dzieje polityczne i struktury władzy. Warszawa 2010, S. 52-53, 57.

12 Szweda, Adam: Po wielkiej wojnie. Zjazdy polsko-krzyżackie w 1411 r. In: Kancelaria wielkich mistrzów i polska kancelaria królewska w XV wieku. Hg. von J. Trupinda. Malbork 2006, S. 267-297; ders.: Zakon Krzyżacki wobec Polski $i$ Litwy w latach 1411-1414. Zeszyty Naukowe Uniwersytetu Jagiellońskiego. Prace Historyczne 41, 2014, z. 2, S. 531-553 (in beiden Arbeiten ältere Fachliteratur).

13 Die Czartoryski-Bibliothek in Krakau, Pergamenturkunden, Nr. 305; Szweda, A.: Organizacja i technika, S. 286; ders.: Was geschieht (im Druck).

14 Zum Hungerkrieg siehe: Biskup, Marian: Wojny Polski z Zakonem Krzyżackim (1308-1521). Gdańsk 1993, S. $100-112$. 
mischen Söldneranführern sowie den königlichen Anhängern ausgestellt worden waren. Sie entstanden auf dem Gebiet Polens, genauer gesagt in Masowien, dessen Herzöge polnische Lehnsmänner waren und durch das die verbündeten Truppen im Krieg gegen Preußen zogen. Zwei Böhmen, Jost von Zelecz (Jošt ze Želče) und Wilhelm Kostka von Postupice (Vilém Kostka z Postupic), stellten ihren Absagebrief in Sochaczew aus, Herzog Konrad V. hingegen in Kolo / Koło, also noch näher an der preußischen Grenze. Ebenfalls aus Kolo / Koło stammt der Brief einer zahlreicheren Gruppe von Adeligen, die ihre Güter auf beiden Seiten der schlesisch-polnischen Grenze hatten und die besagtem Herzog Konrad V. zu Diensten standen. ${ }^{15}$ Die bereits erwähnten Absagebriefe waren auf Deutsch verfasst. Das ist vielleicht auf den berühmten polnischen und europäischen Ritter Zawisza Czarny („Niger“) von Garbow zurückzuführen, der sich eben für diese Sprache entschied, um seinen eigenen Brief am 15. Juli 1414 in Sochaczew auszustellen, und zwar auch im Namen seiner Brüder (es ist auch nicht ausgeschlossen, dass Zawisza an der Anwerbung der böhmischen Söldnertruppen beteiligt war). ${ }^{16}$ Entscheidend dafür waren jedoch eher die langen Aufenthalte Zawiszas am Hofe des Königs von Ungarn Sigismund von Luxemburg und seine Beziehung zur höfisch-ritterlichen Kultur eben im Sinne Luxemburgs. ${ }^{17}$ Aus der starken Bindung zur höfisch-ritterlichen Kultur ergab sich vermutlich auch die Tatsache, dass Zawisza seinen eigenen Absagebrief ausstellte, in dem er seine Unterstützung für den polnischen König erklärte, zumal der berühmte Ritter als Untertan Ladislaus Jagiełłos dazu nicht verpflichtet war, eine solche Urkunde auszustellen. Jedenfalls soll die Wahl der deutschen Sprache betont werden, weil der Gebrauch von Latein in den Urkunden und Briefen als ein wichtiges Indiz für die kulturelle und nationale Identität galt. ${ }^{18}$

Der Hungerkrieg wurde durch den für zwei Jahre in Strasburg geschlossenen und danach mehrmals verlängerten Waffenstillstand beendet. 1422 kam es erneut zu einem Krieg. ${ }^{19}$ Die Initiative dazu ergriff wieder die polnische Partei. Die königliche Kanzlei sorgte dafür, im Inhalt des Briefes einen möglichst breiten Katalog der Gründe aufzuführen, die Ladislaus Jagiełło zu einem bewaffneten Angriff berechtigten ${ }^{20}$. Dem folgte die Absageformel: Ne itaque maiestatis nostre intencio in premissis vobis et ordini vestro sit

15 Szweda, A.: Was geschieht (im Druck) - dort Angabe der Quellen.

16 Biskup, Marian: Miscellanea archiwalne z okresu wojen polsko-krzyżackich z lat 1410-1414. Komunikaty Mazursko-Warmińskie 1960, 2. S. 162: Dem grosmechtigen hern Mecheln homeister in Preusinlant Szawischa Czerny dinst ouch als nu gewant ist Ich los euch wissin das ich wedir euch sain will und helfin dem durchleuchtisken konige von Polan seyner gerechtikeit helfin und wil kein euch domitte bewart sein mit meiner brudir hern Peter und hern Jan von Garbow mit allin unsern (mit korrigierter Zeichensetzung aus der Edition).

17 Możejko, Beata - Szybkowski, Sobiesław - Śliwiński, Błażej: Zawisza Czarny z Garbowa herbu Sulima. Gdańsk 2003, S. 27-28, 68-69 und passim.

18 Mehr dazu siehe: Adamska, Anna: Od taciny do języków wernakularnych - $i$ z powrotem. Język dokumentu średniowiecznego w świetle nowszych badań. In: Kultura pisma w średniowieczu: znane problemy, nowe metody. Hg. von A. Adamska, P. Kras. Colloquia Mediaevalia Lublinensia 2. Lublin 2013, S. 51-100; Szweda, Adam: Latin in Poland in Late Middle Ages - idioma nobilissimum? (im Druck).

19 Zuletzt Bar, Přemysl: Waffenstillstand statt ewiger Frieden? Die Verhandlungen über die Verlängerung des Waffenstillstandes zwischen dem Deutschen Orden und Polen-Litauen (1414-1422). Studia historica Brunensia 66/1, 2019, S. 121-139; siehe auch Biskup, M.: Wojny Polski, S. 113-115. 
incognita, cum omnibus et singulis principibus [...] subditis [...] illisque qui pro nostra facere voluerint maiestate, [...] vos, ordinem vestrum et coadiutores vestros pro tot et tantis opprobriis, molestiis, iniuriis et offensis, quas a vobis pertulimus, diffidamus. ${ }^{21} \mathrm{Da}$ das Original des königlichen Briefes nicht erhalten geblieben ist (bekannt ist er nur ausschließlich aus einem Eintrag im Formelbuch), kann man nichts über seine äußerliche Form sagen.

Den Absagebrief Ladislaus Jagiełłos vom 14. Juli 1422 nutzte Klaus Neitmann als Argument für die Feststellung, dass es notwendig gewesen sei, ihn auch nach Ablauf des Waffenstillstands auszustellen. ${ }^{22}$ Der Inhalt dieser Quelle widerspricht aber derartigen Schlussfolgerungen. Wir finden hier expressis verbis die Anmerkung, dass dies in einer solchen Situation nicht notwendig gewesen sei (licet iam post treugarum expiracionem illud minime expediret). ${ }^{23}$ Es ist aber zu betonen, dass die Praxis in dieser Hinsicht, wie sich 1410 erwiesen hat, nicht einheitlich war.

Im Zusammenhang mit dem Konflikt von 1422 soll auf die Absagebriefe des Hauptmannes von Bromberg (Bydgoszcz) Hannus Birkenhaupt (Janusz Brzozogłowy) sowie seines Interessenten (Burggrafen?) Stefan von Pelszewo hingewiesen werden. Beide, nach demselben Formular angefertigten lateinischen Schriften wurden aus Bromberg abgeschickt. Die Ausstellenden benachrichtigten den Hochmeister, den ganzen Orden und seine Untertanen, dass sie ihnen „absagen“ und ihnen iuxta modum expedicionis generalis schaden werden, bis der König mit ihnen einen Frieden schließe. ${ }^{24}$

1431 begann der Krieg zwischen König Ladislaus Jagiełło und seinem eigenen Bruder, dem litauischen Großfürsten Swidrigal. Dem Kampf schloss sich bald der Deutsche Orden an, der Swidrigal unterstützte. ${ }^{25}$ Mit diesem Konflikt sind die an Swidrigal gerichteten Absagebriefe mehrerer Adeliger aus Kleinpolen verbunden. Sie sind nur aus dem Ordenskanzleibuch bekannt, in dem nur einer von ihnen in extenso berücksichtigt wurde. Der Kastellan von Krakau Nikolaus von Michalow erklärte darin in höflicher Form: Illustri et preclaro principi domino Swidrigal principi Lytuanie etc., Nicolaus de Micholaw castellanus Cracouiensis servicium prout nunc tempus postulat et requirit, dass er ein treuer Diener des Königs sei, den der Großfürst seines väterlichen Erbes beraubt habe. Aus diesem Grund „antwortete“ der Kastellan dem Großfürsten mit einem Krieg und bezeugte ihm gegenüber seine Hochachtung: serenitati vestri et omnibus vestris diffido et me premunio. ${ }^{26}$ Die Gründe, warum eine Reihe von Kriegserklärungen ausgestellt wurde, sind unverständlich. Die Formulierungen aus dem einzigen uns verfügbaren Text ähneln

21 Liber cancellariae Stanislai Ciolek. Ein Formelbuch der polnischen Königskanzlei aus der Zeit der Hussitischen Bewegung (= LC) I. Ed. J. Caro. Wien 1871, S. 79-81, Nr. 42.

22 Neitmann, Klaus: Die Staatsverträge des Deutschen Ordens in Preußen 1230-1449. Studien zur Diplomatie eines spätmittelalterlichen deutschen Territorialstaates. Neue Forschungen zur Brandenburg-Preussischen Geschichte 6. Köln - Wien 1986, S. 365.

23 LC I, S. 79-81, Nr. 42; Szweda, A.: Organizacja i technika, S. 288.

24 Geheimes Staatsarchiv Preussischer Kulturbesitz in Berlin, XX. Hauptabteilung (= GStA-PK, XX. HA), Ordensbriefarchiv (=OBA), Nr. 3817, 3818; Szweda, A.: Organizacja i technika, S. 285.

25 Zuletzt detailliert zu diesen Ereignissen Polechov, Sergej: Nasledniki Vitovta. Dinastičeskaja vojna v Velikom knjažestve Litovskom v 30-je gody XV veka. Moskva 2015.

26 GStA-PK, XX. HA, Ordensfoliant 14, S. 599; Edition (mit Fehlern) Wróbel, Dariusz: Przyczynek prozopograficzny do dziejów tzw. wyprawy tuckiej w 1431 roku. Res Historica 41, 2016, S. 249. 
jenen aus den Urkunden, die von den Söldnern angefertigt wurden. Die kleinpolnischen Ritter waren jedoch keine Söldner. Der Ausstellung der an Swidrigal gerichteten Urkunden basierten eher auf den früheren Beziehungen, welche die polnischen Großen zu Litauen oder auch - was aber weniger wahrscheinlich ist - direkt zum streitsüchtigen Großfürsten Swidrigal unterhielten. ${ }^{27}$ Überzeugend ist auch die Ansicht, dass es im Falle des kleineren Adels vor allem um eine Nachahmung derjenigen Handlungen gehen konnte, die bei den wohlhabenderen Vertretern dieser Schicht wahrzunehmen waren. ${ }^{28}$

Nach einem etwa zweijährigen Waffenstillstand, der 1431 geschlossen worden war, stellten die in den Diensten des polnischen Königs stehenden Söldner ihre Absagebriefe aus. Unter ihnen drängt sich u.a. das Schreiben der Brüder Wincenty und Abraham von Kębłowo (Kiebłowo) in Großpolen in den Vordergrund. Sie sagten dem Hochmeister wegen ihres Dienstes beim König von Polen ab und bezeugten ihre Hochachtung, selbst wenn sie den Ordensvorsteher und seine Untertanen beleidigen sollten..$^{29}$ Auf Papier überliefert ist das Siegel mit dem von den Brüdern von Kębłowo verwendeten Wappen der Wappengemeinschaft Nałęcz. Da im Brief neben ihnen auch andere polnische Adelige und böhmische Söldner erwähnt wurden, kann man annehmen, dass Wincenty und Abraham die ganze Anwerbungsaktion in Gang setzten. ${ }^{30}$ Im Ordenskanzleibuch befinden sich noch weitere Einträge von anderen ähnlichen Urkunden aus dieser Zeit. Absagebriefe wurden damals auch ausgestellt von: dem Herzog von Pommern-WolgastStolp Bogislaw IX., der ihm unterstehenden Stadt Stargard, den pommerschen Rittern und noch von einer Gruppe böhmischer Söldner. Der letztgenannte Brief wurde ähnlich wie das Schreiben der Brüder von Kębłowo auf Latein verfasst, die pommerschen Briefe hingegen in der niederdeutschen Sprache. ${ }^{31}$

1435 wurde der nächste Friedensvertrag geschlossen, der kaum 20 Jahre andauerte. Die Ursache des erneut ausgebrochenen Krieges war der Konflikt des Deutschen Ordens mit seinen Untertanen. Die Vertreter der preußischen Stände wandten sich mit der Bitte um Unterstützung an den polnischen König Kasimirus den Jagiellonen, und der Herrscher und die polnischen Eliten beschlossen diese Gelegenheit zu nutzen, um sich PreuBen unterzuordnen. ${ }^{32}$ Der in diesem Zusammenhang ausgestellte Absagebrief ist nur aus einem Eintrag im polnischen Kanzleibuch bekannt. Er entstand selbstverständlich auf Latein und führte Argumente der polnischen Partei an, die sich sogar fürs Fabulieren entschied, weil sie dem Orden die Schuld für die Missachtung des Friedensbeschlusses von 1435 nicht nachweisen konnte. Zusätzlich wurde der Brief noch zurückdatiert und erst nach dem 3. März angefertigt, d.i. nach den abgeschlossenen Gesprächen mit der

27 Szweda, A.: Organizacja i technika, S. 289-290.

28 Wróbel, D.: Przyczynek prozopograficzny, S. 243.

29 GStA-PK, XX. HA, OBA, Nr. 6568: vos wenerabilem magistrum domus Theutunicorum de Prussia generalem [...] erga serenissimum dominum nostrum, dominum regem Polonie, nostrum dominum gratiosissimum diffidamus per presentes; velit Deus quidquid faciemus apud vos, honores nostros faciemus premunitos.

30 Szweda, A.: Organizacja i technika, S. 285.

31 GStA-PK, XX. HA, Ordensfoliant 14, S. 736-738.

32 Biskup, Marian: Zjednoczenie Pomorza Wschodniego z Polska w potowie XV wieku. Warszawa 1959, S. 149-220, 278-331; ders.: Trzynastoletnia wojna z Zakonem Krzyżackim 1454-1466. Warszawa 1967, S. 29-172. 
Gesandtschaft der preußischen Stände, obwohl in seiner Datierung der 22. Februar 1454 aufgeführt wird. ${ }^{33}$ Die Absageformel im besagten Brief lautet folgendermaßen: Sed cum vos ipsi huius rei occassio estis et origo, cum omnibus et singulis principibus, fratris nostris carissimis, baronibus, militibus, nobilibus, terrigenis regni nostri et subditis ac illis, qui pro nostra facere voluerint magestate, vos et ordinem vestrum condam Prussie et vobis adherentes pro tot et tantis iniuriis, molestiis et offensis, nobis et subditis nostris ut supra per vos irrogatis, diffidamus. ${ }^{34}$

Kurz danach stellten die vom Preußischen Bund gegen den Orden angeworbenen polnischen und böhmischen Söldner ihre eigene Briefe aus. Einer von ihnen wurde auf Deutsch niedergeschrieben. Sein Aussteller war der Wojewode von Brest und Hauptmann von Bromberg Mikołaj Szarlejski von Ścibórz. ${ }^{35}$ Die Anschrift war höflich und vornehm: Dem erwirdigen und grosmechtigen herren Ludwigen von Erlichshwsen homeister deutsches ordens wir Niclos von Stiborsse andirs von Scharley [etc.] unsirn dinst als die gelouffte angehorit. Dem folgte eine relativ umfangreiche Begründung seiner Entscheidung (vor allem die Betonung des Unrechts der vom Orden gestifteten preußischen Städte) und danach die folgende Absageformel: und durch der wille wir euch und allen den euwirn vorgenanten mit allen den unsern vorgeschribenen frunden und bey den vorgenanten unsirn frunden und brudern der lande und stete des Bundis von Preussen endsagen und unsern allen kegen euch und euwirn orden an unsern eren vorwaren. ${ }^{36}$ Unterhalb des Textes blieb das beschädigte Wappensiegel des Ausstellenden erhalten. Die Wahl der deutschen Sprache ist vermutlich auf die früheren engen Kontakte Mikołaj Szarlejskis zurückzuführen, die er noch mit dem Hof Sigismunds von Luxemburg und Preußens gepflegt hatte.

Interessanter jedoch sind die Briefe anderer polnischer Söldner. Sie entstanden nicht, wie man erwarten könnte, auf Latein bzw. Deutsch, sondern in jener Sprache, die von Wilhelm Rautenberg, der die Absagebriefe von 1454 analysierte, als „Übergangsdialekt Tschechisch - Polnisch“ bezeichnet wurde. ${ }^{37}$ Dazu war es zweifellos unter dem Einfluss der aus Böhmen stammenden Söldner gekommen. Der Gebrauch der böhmischen Sprache, die in den Aktenquellen schon im 14. Jahrhundert auftauchte, war nicht verwunderlich. Die Feindschaftserklärung der im Dienste des polnischen Königs stehenden böhmischen Söldner an den Hochmeister stammt vermutlich schon aus den Jahren 14101414. ${ }^{38}$ Die im Dienste des Preußischen Bundes stehenden böhmischen Söldner stellten ihre Absagebriefe in ihrer Muttersprache aus, was die polnischen Söldner nachahmten.

33 Die Staatsverträge des Deutschen Ordens in Preussen im 15. Jahrhundert II. Ed. E. Weise. Marburg 1955 , S. 116-120, Nr. 289; Szweda, A.: Organizacja i technika, S. 287-288; ders.: Was geschieht (im Druck).

34 Die Staatsverträge II, S. 116-120, Nr. 289.

$35 \mathrm{Zu}$ ihm siehe: Szybkowski, Sobiesław: Kujawska szlachta urzędnicza w późnym średniowieczu (1370-1501). Gdańsk 2006, S. 646-647.

36 GStA-PK, XX. HA, OBA, Nr. 12894.

37 Rautenberg, Wilhelm: Böhmische Söldner im Ordensland Preußen. Ein Beitrag zur Söldnergeschichte des 15. Jahrhunderts, vornehmlich des 13jährigen Städtekriegs 1454-1466. Hamburg 1953 [Dissertation, Typoskript] (Anmerkungen und Anhang) Anhang, S. 8.

38 Biskup, M.: Miscellanea archiwalne, S. 162 - Im Brief fehlt die Datierung. Auf die Jahre 1410-1414 wies der Herausgeber hin. Es ist aber nicht ausgeschlossen, dass das Schreiben erst aus den Jahren 1431-1433 stammt, worauf die Elemente des Formulars hindeuten und was die Verbindung zum Dienst beim polnischen König Władysław nicht ausschließt. 
Sie stellten am 25. März 1454 in Thorn fünf Absagebriefe aus. ${ }^{39}$ Die Herausgeber der Regeste aus dem Ordensarchiv bezeichnen sie fälschlicherweise als böhmische Söldner, und die Sprache ihrer Erklärungen als Böhmisch. ${ }^{40}$ Richtig identifiziert sie Marian Biskup, der sich mit dem dreizehnjährigen Krieg auseinandersetzte, doch auch ihm zufolge wurden die von ihnen ausgestellten Briefe auf Böhmisch niedergeschrieben. ${ }^{41}$ Wenn wir die einzelnen Briefe der polnischen und böhmischen Söldner miteinander vergleichen, sind die Unterschiede jedoch sehr deutlich (abgesehen von den Anforderungen an die Quellenpublikation selbst).

\begin{tabular}{|c|c|}
\hline $\begin{array}{l}\text { Brief der polnischen Söldner - Mikołaj Lit- } \\
\text { wos' von Kazanowo und anderer, Thorn, } \\
\text { 25. März } 1454 \text {. }\end{array}$ & $\begin{array}{l}\text { Brief des böhmischen Söldners - Jan von } \\
\text { Horky, Marienwerder, 30. März } 1454 \text {. }\end{array}$ \\
\hline $\begin{array}{l}\text { My Nicolas Litfos z Kazanowa, Petr Pyw- } \\
\text { ko z Wyeseley Hory, Skarbek z Hrodzyska, } \\
\text { Jen Sroczkowsky, Petr Sbyskowsky, Pawel } \\
\text { Zelkothi, Jen Zychorzky, Nycolas s Byelyn, } \\
\text { Marczynek s Byeleyowsky, Cyrwyensky, } \\
\text { Opalacz, Szwyraczky, Morawyczky, Bel- } \\
\text { dowsky, Slawyensky, Zaclika Crzywyeczky, } \\
\text { Hector, Hynathko, Jen Paczoska, Jacub } \\
\text { Goreczky, Pnyewsky, Petr Moczygaba } \\
\text { s Kromnyka y gym wsseczczy wstrzeha- } \\
\text { my proczyw wam mystrzowyy prwskyemu } \\
\text { y kwnthorom y ycho wszeczkym y po(mo) } \\
\text { cznyky wedle panow swych y syemye tey } \\
\text { pruskye tak dluho dokad smy wyegych } \\
\text { slusbye. Atho smy sw pyeczeth przylebyly. } \\
\text { Dan Thorwny w pondely den w Swyez- } \\
\text { towyenye Matki Pozei. }\end{array}$ & $\begin{array}{l}\text { Welebnemu a mnoho mocznemu panu } \\
\text { Ludwikowi mistrowi zakona niemeczkeho } \\
\text { ja Jan z Horky s swimi sewssiemi sluzebniki } \\
\text { wystrziham sie a swu czest ohrazugi proty } \\
\text { tobie y proty twim wssiem pomocznikuom } \\
\text { y sluzebnikuom swietczkim y duchownym } \\
\text { wedle mnoho mocznych statecznych ssle- } \\
\text { chetnych a opatrnych panow ritierzow, pa- } \\
\text { nossy, zeman y miesstyan zemie pruskey } \\
\text { panow nassych dokudz sme v nych w gich } \\
\text { sluzbie wam nechczem nyczimcz wynni } \\
\text { byti. Datum Mariewerder feria VI post Sa- } \\
\text { lus populi anno etc. LIIII }\end{array}$ \\
\hline
\end{tabular}

Bemerkenswert sind hier nicht nur die Formularunterschiede (bezüglich des wichtigen Elements der Bezeugung der eigenen Hochachtung), sondern auch die allgemeine Reife der Sprache. Der „böhmische“ Brief entspricht anderen ähnlichen und in der gleichen Zeitspanne in Böhmen entstandenen Quellen genau. ${ }^{42}$ Man sollte also Rautenberg beipflichten, jedoch mit dem Vorbehalt, dass die Absagebriefe polnischer Söldner von 1454 in sprachwissenschaftlicher Hinsicht gründlich untersucht werden sollten. Es ist jedenfalls der erste effektive Versuch, die Vernakulärsprache in das polnische Aktenmaterial

39 GStA-PK, XX. HA, OBA, Nr. 12895.

40 Regesta historico-diplomatica Ordinis S. Mariae Theutonicorum I. Edd. E. Joachim - W. Hubatsch. Göttingen 1948, S. 839, Nr. 12895.

41 Biskup, M.: Trzynastoletnia wojna, S. 173, Anm. 143.

42 Siehe beispielsweise: Listář a listinář Oldřicha z Rožmberka II. Ed. B. Rynešová. Praha 1932, S. 240, Nr. 264. 
einzuführen (abgesehen von den Gerichtseidesformeln). Auf Ebene der königlichen Kanzlei erfolgte dies ein paar Jahrzehnte später.

Denn erst an der Wende vom zweiten zum dritten Jahrzehnt des 16. Jahrhunderts erscheinen auf Polnisch geschriebene Briefquellen. Dazu gehören die Absagebriefe, die anlässlich des Ausbruchs des letzten Krieges zwischen Polen und dem Deutschen Orden in den Jahren 1519-1521 angefertigt wurden, der die Versuche des Hochmeisters Albrecht von Hohenzollern, sich von der polnischen Krone zu befreien und die Bedingungen des Zweiten Thorner Friedens von 1466 zu revidieren, beendete..$^{43} \mathrm{Zu}$ diesem Zeitpunkt wurde auch erstmals der Versuch ihrer Formalisierung unternommen, die einzelnen eigentlichen Schreiben trug man nämlich in die Kronmetrik ein. Hier befinden sich die am 10. März 1520 aus Graudenz abgeschickten Briefe des Rottmeisters der Trabantenrotte Jan Trzepiński (odpowiedz drabska, „Absage der Trabanten“), des Rottmeisters der Reiterrotte Jakub Sęcygniowski (otpowyedz jezdnich, „Absage der Reiter“) und der königlichen Hofleute Stanisław, Jan und Piotr (otpowyedz dworzanska, „Absage der Hofleute“). ${ }^{44}$

Ein wenig später, jedoch noch im selben Jahr 1520, trug man in Thorn auf Anordnung des Kanzlers Krzysztof Szydłowiecki, der die formalen Fragen der Kriegsführung kodifizieren wollte, die genannten Briefe erneut in die Kronmetrik ein, diesmal ohne die Namen der Ausstellenden, wodurch ihnen der Charakter eines Formulars verliehen wurde. Zuerst führte man das Beispiel eines Absagebriefes der königlichen Hofleute an (najpierwej na który sposób Króla Jego Mitości dworzanie na ten czas panu mistrzowi odpowiadali), dann der Reiterrottmeister (na thenze sposób odpowyedz rothmystrzow jeznych), und schließlich der Trabantenrottmeister (othpowyedz rothmistrzow drabskych).$^{45}$ Diese Schreiben hatten trotz unterschiedlicher Gruppen von Ausstellenden einen identischen Inhalt. Der Ausstellende sage wegen seines Dienstes beim König Sigismund dem Alten zusammen mit seinen Begleitern, Untertanen und Helfern sowie deren Helfern dem Hochmeister Albrecht von Hohenzollern und allen seinen Untertanen ab (odpowiedam tim to listem), womit er seine Hochachtung bezeuge (moye czescz ogradzaiancz), solange bis der König mit ihnen Krieg führe.

Die hier geschilderten Quellen gehören zur Gruppe der frühesten auf Polnisch niedergeschriebenen Erzeugnisse der königlichen Kanzlei, in der diese Sprache erstmals 1511 verwendet wurde und noch innerhalb der folgenden drei Jahrzehnte relativ selten vorkam. ${ }^{46}$

Unter den in Originalfassung erhaltenen polnischen Absagebriefen dieser Zeit stellen die meisten den Formulartyp dar, der denjenigen ähnelte, die sich in der Kronmetrik

43 Biskup, Marian: „Wojna pruska“ czyli walka Polski z zakonem krzyżackim z lat 1519-1521. U źródeł sekularyzacji Prus Krzyżackich. Olsztyn 1991.

44 Archiwum Główne Akt Dawnych, Metryka Koronna (= AGAD, MK) 34, fol. 287v-288v (edycja - Acta Tomiciana V. Ed. T. Działyński. Kórnik 1855, S. 132-133 - dort ohne Jahresdaten). Zum Hintergrund der Ausstellung von diesen Briefen siehe: Biskup, M.: „Wojna pruska“, S. 149.

45 AGAD, MK 37, fol. 1-2. Entgegen Karol Łopateckis Ausführungen (Łopatecki, K.: „Disciplina militaris“, S. 46) stellt der Brief von Mikołaj Skotnicki, der in den Rezessen der preußischen Stände - Akta stanów Prus Królewskich VII. Edd. M. Biskup - I. Janosz-Biskupowa. Warszawa 1986, S. 378 - eingetragen ist, einen anderen Formulartyp als die Akten dar, die sich in der Kronmetrik befinden. Es ist auch ein anderer Brief Skotnickis als der im Original erhaltene und von M. Biskup herausgegebene Brief (siehe unten). 
befinden. ${ }^{47}$ Einige waren jedoch anders abgefasst. So bemerkte beispielsweise der Truchsess von Ciechanów Janusz Łaniewski lediglich, dass man dem Hochmeister nur wegen des Dienstes beim König „absage“, und wiederholte, dass er dies wedtug sprawiedliwości króla jego mitości, króla polskiego tue. ${ }^{48}$ Besondere Aufmerksamkeit verdienen zwei Briefe, deren Datierungsformeln gereimt sind. Der Ausstellende des ersten von ihnen war der Truchsess von Sandomierz Mikołaj Skotnicki, der an der Spitze der Reiter- und Trabantenrotte stand, die Empfänger waren hingegen der Hochmeister und der pomesanische Bischof Hiob Dobeneck, der ihn in dieser Phase des Konfliktes unterstützte. Der Brief wurde vor dem 29. Dezember 1519 aus Pakost in Nordgroßpolen abgeschickt. Die erwähnte Datierung lautet wie folgt:

Data z Pakosczy, yusch sye nadzyeway gosczy, badzyem boh da w waschey mylosczy, bo sye to dzyeye prze wasche szlosczy ysz nyeczynyczye dosczy swey powynnosczy ${ }^{49}$ [gegeben in Pakost, erwarte die Gäste, wir bleiben, so Gott will, in ihrer Gunst, das geschieht wegen eurer Boshaftigkeit, weil ihr eure Pflicht nicht erfüllt]. In diese Übersetzung ins Deutsche konnten leider keine Reime übernommen werden.

Das zweite Beispiel stammt aus einem Brief des Rottmeisters sowohl der Reiter als auch der Trabanten Ligęza Zbożny. Dieses Schreiben wurde Ende Dezember 1519 ebenfalls aus Mogilno abgeschickt (auch Nordgroßpolen). Hier sieht die Datierung folgendermaßen aus: Datha w Mogylnye, o tho szye posztharamy pylnye, ze v vaszey myloszczy badzyemy barzo szylnye, lyatha bozego daly pan bog forthunego ${ }^{50}$ [gegeben in Mogilno, wir versuchen es unbedingt, in eurer Gunst sehr stark zu bleiben, im - so Gott will - glücklichen Jahr des Herrn].

Marian Biskup, dem Herausgeber des Briefes von Mikołaj Skotnicki zufolge, macht die gereimte Datierung den Inhalt des Briefes eindeutig lebendig ${ }^{51}$. Karol Łopatecki betrachtet sie dagegen als „Drohung," 52 was - wie man erwarten kann - die allgemeine Aussage des Briefes bekräftigen sollte. Es scheint, dass man hier eher von Ironie oder auch Hohn sprechen kann, was den Geist des Gegners schwächen und die Hoffnung der eigenen Truppen auf einen Sieg steigern sollte.

Bemerkenswert ist auch der vermutlich aus dem Jahr 1428 stammende Absagebrief des Herzogs von Masowien Janusz des Älteren. Er ist bekannt aus dem Formelbuch bekannt und rekurriert nicht auf die Beziehungen zwischen Polen und dem Deutschen Orden, zumal Konrad, der Herzog von Schlesien sein Empfänger war (es ist jedoch schwierig, ihn eindeutig zu identifizieren). Sehr ungewöhnlich ist hier die Begrüßungsanrede : pro salute

47 GStA-PK, XX. HA, OBA, Nr. 24465 - Sammlung etlicher derartiger Akten, teilweise aber auch auf Böhmisch; vgl. Biskup, Marian: Polskie listy dowódców Zygmunta I z Prus z okresu wojny z Zakonem Krzyżackim (1519-1521). In: Kultura średniowieczna i staropolska. Hg. von D. Gawin. Warszawa 1991, S. 504.

48 GStA-PK, XX. HA, OBA, Nr. 24465, fol. 17. Im Brief fehlt die Datierungsformel, er wurde aber höchstwahrscheinlich Ende Dezember 1519 aus Thorn abgeschickt. - Biskup, M.: „Wojna pruska“, S. 85.

49 GStA-PK, XX. HA, OBA, Nr. 24465, fol. 21 (Edition - Biskup, M.: Polskie listy, S. 506-507).

50 GStA-PK, XX. HA, OBA, Nr. 24465, fol. 23.

51 Biskup, M.: Polskie listy, S. 504.

52 Łopatecki, K.: „Disciplina militaris“, S. 45. 
gladium bis acutum. ${ }^{53} \mathrm{Im}$ ganzen Quellenmaterial entspricht dies keiner ähnlichen Stelle, ähnelt aber dem Fragment der „Bekenntnisse“ des Augustinus von Hippo (Confessiones, lib. XII, cap. XIV):

Mira profunditas eloquiorum tuorum, quorum ecce ante nos superficies blandiens parvulis: sed mira profunditas, deus meus, mira profunditas! horror est intendere in eam, horror honoris et tremor amoris. odi hostes eius vehementer: o si occidas eos de gladio bis acuto, et non sint hostes eius!

In Übersetzung ins Deutsche: „O wunderbare Tiefe deiner Offenbarungen, deren Oberfläche, die vor unsern Augen liegt, uns Unmündigen gefällt. Aber o wunderbare Tiefe, mein Gott, o wunderbare Tiefe! Ich erschrecke, mich in sie zu versetzen; Schauer der Ehrfurcht und Beben der Liebe ergreift mich. Ihre Feinde hasse ich ungemein: o daß du sie mit dem zweischneidigen Schwerte tötetest, so daß sie nicht mehr ihre Feinde wären!" 54

„Das zweischneidige Schwert“ im Inhalt des Absagebriefes zeugt eher davon, dass dieses Fragment des Formelbuches von einem gelehrten Priester angefertigt wurde und sich vermutlich nicht auf die faktischen Ereignisse bezog.

Zusammenfassend muss man feststellen, dass die polnischen Absagebriefe aus der Zeit der Kriege mit dem Deutschen Orden einen integralen Bestandteil der zeitgenössischen Kriegs- und Politikkultur bildeten. Angesichts der verschiedenen Varianten des Formulars wurden sie parallel zu den Nachbarländern angefertigt. Die königlichen Briefe (der einzige als Originalschrift erhaltene Brief wurde auf Pergament niedergeschrieben) zählen die Gründe auf, die die Kriegsentscheidung des Herrschers rechtfertigten. Die Briefe anderer Kriegsteilnehmer (konsequenterweise auf Papier niedergeschrieben, mit Siegeln unterhalb des Textes, also die ersten litterae patentes, die nicht versiegelt wurden) betonten den Dienst für den Herrscher, wodurch die Beteiligung am Kriegsgeschehen sie nicht beleidigte. Obwohl vor allem die Söldner im Sinne des Rechts und der Gewohnheit dazu verpflichtet waren, eigene Schriftstücke auszustellen, stammen solche Briefe auch aus der Hand von Rittern, die diese Gewohnheit auf fremden Höfen (wie Zawisza Czarny) oder von Grenzbeamten (Janusz Brzozogłowy) kennen lernten. Die Sprache der polnischen Absagebriefe war bis Mitte des 15. Jahrhunderts vornehmlich Latein (was charakteristisch für die zeitgenössische polnische Diplomatie war), selten auch Deutsch. Im Jahr 1454 entstanden die Briefe polnischer im Dienste des Preußischen Bundes stehender Söldner, die unter dem Einfluss der böhmischen Rottmeister in der ungelenken polnischen Sprache (im böhmisch-polnischen Dialekt?) verfasst wurden. Der letzte Krieg gegen dem Orden in den Jahren 1519-1521 führte dagegen zur Herausbildung eines polnischen Formulars des Absagebriefes. Die königliche Kanzlei bemühte sich mit gewissem Erfolg, sie zu vereinheitlichen.

Der Rückhalt der königlichen Heere durch die Söldnerrotten bewirkte, dass aus diesem Konflikt eine Vielzahl der hier analysierten Quellen erhalten geblieben ist. Es ist

53 Libri formularum saeculi XV. Ed. B. Ulanowski. Kraków 1888, S. 64, Nr. 126.

54 St. Augustinus: Confessiones - lateinisch und deutsch. Übersetzt von J. Bernhart. München 1980, S. 696-697. 
aber gleichzeitig das Ende ihrer Produktion. Dies ergab sich dagegen aus der kurz nach dem Ende des letzten zwischen Polen und dem Deutschen Orden geführten Krieges erfolgten Umstrukturierung des Militärs. ${ }^{55}$

\section{Polské odpovědní listy ve válce s řádem německých rytî́ru}

Polské odpovědní listy z období válečných konfliktů s řádem německých rytírư byly nedílnou součástí tehdejší politické a vojenské kultury. Mimo změn ve formuláři byly tyto listy vyhotovovány podobným způsobem jako v sousedních zemích. V královských listech (jediný originální list byl sepsán na pergamenu) jsou vypočítávány důvody, kterými se ospravedlňují připravovaná vojenská opatření. V listech (důsledně papírové s pečetí pod textem, bez uzavírací pečeti, tudíž to byly litterae patentes) ostatních účastníků válečných akcí byla zdůrazňována služba panovníkovi. Tímto argumentem se vydavatelé odpovědních listů snažili ospravedlnit, že účast na násilných akcích není ke škodě jejich cti. Ačkoliv na základě práva a zvyklostí byl tento právní akt závazný zejména pro žoldnéře, podobné listy pocházely rovněž od rytî́ro kt, kteří se s tímto zvykem setkali na cizích dvorech (Záviš Černý), nebo od úředníků v příhraniční oblasti (Jan Brzozogłowy). Polské odpovědní listy byly do poloviny 15. století psány převážně latinským (což bylo pro tehdejší polskou diplomatiku typické) a jen zř́ídkakdy německým jazykem. Z roku 1454 se dochovaly listy polských žoldnéřu ve službách Pruského svazu, kteří je psali pod vlivem českých rotmistrů neobratnou polštinou („polsko-českým dialektem“?). Během poslední války s řádem v letech 1519-1521 se vyvinul polský formulář odpovědního listu a královská kancelář usilovala o jeho sjednocení, byt jen s částečným úspěchem.

55 Łopatecki, K.: „Disciplina militaris“, S. 48. 
